\title{
Racism and Research: The Case of the Tuskegee Syphilis Study
}

\section{Citation}

Brandt, Allan M. 1978. "Racism and research: The case of the Tuskegee Syphilis study." The Hastings Center Report 8(6): 21-29.

\section{Published Version}

http://www.jstor.org/stable/3561468

\section{Permanent link}

http://nrs.harvard.edu/urn-3:HUL.InstRepos:3372911

\section{Terms of Use}

This article was downloaded from Harvard University's DASH repository, and is made available under the terms and conditions applicable to Other Posted Material, as set forth at http:// nrs.harvard.edu/urn-3:HUL.InstRepos:dash.current.terms-of-use\#LAA

\section{Share Your Story}

The Harvard community has made this article openly available.

Please share how this access benefits you. Submit a story.

Accessibility 


\section{Racism and Research: The Case of the Tuskegee Syphilis Study \\ by $A L L A N$ M. BRANDT}

I

1932 the U.S. Public Health Service (USPHS) initiated an experiment in Macon County, Alabama, to determine the natural course of untreated, latent syphilis in black males. The test comprised 400 syphilitic men, as well as 200 uninfected men who served as controls. The first published report of the study appeared in 1936 with subsequent papers issued every four to six years, through the 1960 s. When penicillin became widely available by the early 1950 s as the preferred treatment for syphilis, the men did not receive therapy. In fact on several occasions, the USPHS actually sought to prevent treatment. Moreover, a committee at the federally operated Center for Disease Control decided in 1969 that the study should be continued. Only in 1972, when accounts of the study first appeared in the national press, did the Department of Health, Education and Welfare halt the experiment. At that time seventy-four of the test subjects were still alive; at least twenty-eight, but perhaps more than 100, had died directly from advanced syphilitic lesions. ${ }^{1}$ In August 1972, HEW appointed an investigatory panel which issued a report the following year. The panel found the study to have been "ethically unjustified," and argued that penicillin should have been provided to the men."

This article attempts to place the Tuskegee Study in a historical context and to assess its ethical implications. Despite the media attention which the study received, the HEW Final Report, and the criticism expressed by several professional organizations, the experiment has been largely misunderstood. The most basic questions of how the study was undertaken in the first place and why it continued for forty years were never addressed by the HEW investigation. Moreover, the panel misconstrued the nature of the experiment, failing to consult important documents available at the National Archives which bear significantly on its ethical assessment. Only by examining the specific ways in which values are engaged in scientific research can the study be understood.

\section{Racism and Medical Opinion}

A brief review of the prevailing scientific thought regarding race and heredity in the early twentieth century is fundamental for an understanding of the Tuskegee Study. By the turn of the century, Darwinism had provided a new ration-

Allan M. BRANDT is a doctoral candidate in the Department of History, Columbia University. He is presently writing a social history of venereal disease in the United States. Mr. Brandt was a student intern at The Hastings Center in 1977. ale for American racism. ${ }^{3}$ Essentially primitive peoples, it was argued, could not be assimilated into a complex, white civilization. Scientists speculated that in the struggle for survival the Negro in America was doomed. Particularly prone to disease, vice, and crime, black Americans could not be helped by education or philanthropy. Social Darwinists analyzed census data to predict the virtual extinction of the Negro in the twentieth century, for they believed the Negro race in America was in the throes of a degenerative evolutionary process. ${ }^{4}$

The medical profession supported these findings of late nineteenth- and early twentieth-century anthropologists, ethnologists, and biologists. Physicians studying the effects of emancipation on health concluded almost universally that freedom had caused the mental, moral, and physical deterioration of the black population. ${ }^{5}$ They substantiated this argument by citing examples in the comparative anatomy of the black and white races. As Dr. W. T. English wrote: "A careful inspection reveals the body of the negro a mass of minor defects and imperfections from the crown of the head to the soles of the feet. . ." " Cranial structures, wide nasal apertures, receding chins, projecting jaws, all typed the Negro as the lowest species in the Darwinian hierarchy. ${ }^{7}$

Interest in racial differences centered on the sexual nature of blacks. The Negro, doctors explained, possessed an excessive sexual desire, which threatened the very foundations of white society. As one physician noted in the Journal of the American Medical Association, "The negro springs from a southern race, and as such his sexual appetite is strong; all of his environments stimulate this appetite, and as a general rule his emotional type of religion certainly does not decrease it." ${ }^{8}$ Doctors reported a complete lack of morality on the part of blacks:

Virtue in the negro race is like angels' visits-few and far between. In a practice of sixteen years I have never examined a virgin negro over fourteen years of age. ${ }^{9}$

A particularly ominous feature of this overzealous sexuality, doctors argued, was the black males' desire for white women. "A perversion from which most races are exempt," wrote Dr. English, "prompts the negro's inclination towards white women, whereas other races incline towards females of their own."10 Though English estimated the "gray matter of the negro brain" to be at least a thousand years behind that of the white races, his genital organs were overdeveloped. As Dr. William Lee Howard noted:

The attacks on defenseless white women are evidences of racial instincts that are about as amenable to ethical culture as is the inherent odor of the race.... When education will 
reduce the size of the negro's penis as well as bring about the sensitiveness of the terminal fibers which exist in the Caucasian, then will it also be able to prevent the African's birthright to sexual madness and excess. ${ }^{11}$

One southern medical journal proposed "Castration Instead of Lynching," as retribution for black sexual crimes. "An impressive trial by a ghost-like kuklux klan [sic] and a 'ghost' physician or surgeon to perform the operation would make it an event the 'patient' would never forget," noted the editorial. ${ }^{12}$

According to these physicians, lust and immorality, unstable families, and reversion to barbaric tendencies made blacks especially prone to venereal diseases. One doctor estimated that over 50 percent of all Negroes over the age of twenty-five were syphilitic. ${ }^{13}$ Virtually free of disease as slaves, they were now overwhelmed by it, according to informed medical opinion. Moreover, doctors believed that treatment for venereal disease among blacks was impossible, particularly because in its latent stage the symptoms of syphilis become quiescent. As Dr. Thomas W. Murrell wrote:

They come for treatment at the beginning and at the end. When there are visible manifestations or when harried by pain, they readily come, for as a race they are not averse to physic; but tell them not, though they look well and feel well, that they are still diseased. Here ignorance rates science a fool. ... ${ }^{14}$

Even the best educated black, according to Murrell, could not be convinced to seek treatment for syphilis. ${ }^{15}$ Venereal disease, according to some doctors, threatened the future of the race. The medical profession attributed the low birth rate among blacks to the high prevalence of venereal disease which caused stillbirths and miscarriages. Moreover, the high rates of syphilis were thought to lead to increased insanity and crime. One doctor writing at the turn of the century estimated that the number of insane Negroes had increased thirteen-fold since the end of the Civil War. ${ }^{16} \mathrm{Dr}$. Murrell's conclusion echoed the most informed anthropological and ethnological data:

So the scourge sweeps among them. Those that are treated are only half cured, and the effort to assimilate a complex civilization driving their diseased minds until the results are criminal records. Perhaps here, in conjunction with tuberculosis, will be the end of the negro problem. Disease will accomplish what man cannot do. ${ }^{17}$

This particular configuration of ideas formed the core of medical opinion concerning blacks, sex, and disease in the early twentieth century. Doctors generally discounted socioeconomic explanations of the state of black health, arguing that better medical care could not alter the evolutionary scheme. ${ }^{18}$ These assumptions provide the backdrop for examining the Tuskegee Syphilis Study.

\section{The Origins of the Experiment}

In 1929, under a grant from the Julius Rosenwald Fund, the USPHS conducted studies in the rural South to determine the prevalence of syphilis among blacks and explore the possibilities for mass treatment. The USPHS found Macon County, Alabama, in which the town of Tuskegee is located, to have the highest syphilis rate of the six counties surveyed. The Rosenwald Study concluded that mass treatment could be successfully implemented among rural blacks. ${ }^{19}$ Although it is doubtful that the necessary funds would have been allocated even in the best economic conditions, after the economy collapsed in 1929, the findings were ignored. It is, however, ironic that the Tuskegee Study came to be based on findings of the Rosenwald Study that demonstrated the possibilities of mass treatment.

Three years later, in 1932, Dr. Taliaferro Clark, Chief of the USPHS Venereal Disease Division and author of the Rosenwald Study report, decided that conditions in Macon County merited renewed attention. Clark believed the high prevalence of syphilis offered an "unusual opportunity" for observation. From its inception, the USPHS regarded the Tuskegee Study as a classic "study in nature,"* rather than an experiment. ${ }^{20}$ As long as syphilis was so prevalent in Macon and most of the blacks went untreated throughout life, it seemed only natural to Clark that it would be valuable to observe the consequences. He described it as a "ready-made situation." ${ }^{21}$ Surgeon General H. S. Cumming wrote to R. R. Moton, Director of the Tuskegee Institute:

The recent syphilis control demonstration carried out in Macon County, with the financial assistance of the Julius Rosenwald Fund, revealed the presence of an unusually high rate in this county and, what is more remarkable, the fact that 99 per cent of this group was entirely without previous treatment. This combination, together with the expected cooperation of your hospital, offers an unparalleled opportunity for carrying on this piece of scientific research which probably cannot be duplicated anywhere else in the world. ${ }^{22}$

Although no formal protocol appears to have been written, several letters of Clark and Cumming suggest what the USPHS hoped to find. Clark indicated that it would be important to see how disease affected the daily lives of the men:

The results of these studies of case records suggest the desirability of making a further study of the effect of untreated syphilis on the human economy among people now living and engaged in their daily pursuits. ${ }^{23}$

It also seems that the USPHS believed the experiment might demonstrate that antisyphilitic treatment was unnecessary. As Cumming noted: "It is expected the results of this study may have a marked bearing on the treatment, or conversely the non-necessity of treatment, of cases of latent syphilis." ${ }^{24}$

The immediate source of Cumming's hypothesis appears to have been the famous Oslo Study of untreated syphilis. Between 1890 and 1910, Professor C. Boeck, the chief of the

*In 1865, Claude Bernard, the famous French physiologist, outlined the distinction between a "study in nature" and experimentation. A study in nature required simple observation, an essentially passive act, while experimentation demanded intervention which altered the original condition. The Tuskegee Study was thus clearly not a study in nature. The very act of diagnosis altered the original conditions. "It is on this very possibility of acting or not acting on a body," wrote Bernard, "that the distinction will exclusively rest between sciences called sciences of observation and sciences called experimental." 
Oslo Venereal Clinic, withheld treatment from almost two thousand patients infected with syphilis. He was convinced that therapies then available, primarily mercurial ointment, were of no value. When arsenic therapy became widely available by 1910, after Paul Ehrlich's historic discovery of "606," the study was abandoned. E. Bruusgaard, Boeck's successor, conducted a follow-up study of 473 of the untreated patients from 1925 to 1927 . He found that 27.9 percent of these patients had undergone a "spontaneous cure," and now manifested no symptoms of the disease. Moreover, he estimated that as many as 70 percent of all syphilitics went through life without inconvenience from the disease. ${ }^{25}$ His study, however, clearly acknowledged the dangers of untreated syphilis for the remaining 30 percent.

Thus every major textbook of syphilis at the time of the Tuskegee Study's inception strongly advocated treating syphilis even in its latent stages, which follow the initial inflammatory reaction. In discussing the Oslo Study, Dr. J. E. Moore, one of the nation's leading venereologists wrote, "This summary of Bruusgaard's study is by no means intended to suggest that syphilis be allowed to pass untreated." ${ }^{26}$ If a complete cure could not be effected, at least the most devastating effects of the disease could be avoided. Although the standard therapies of the time, arsenical compounds and bismuth injection, involved certain dangers because of their toxicity, the alternatives were much worse. As the Oslo Study had shown, untreated syphilis could lead to cardiovascular disease, insanity, and premature death. ${ }^{27}$ Moore wrote in his 1933 textbook:

Though it imposes a slight though measurable risk of its own, treatment markedly diminishes the risk from syphilis. In latent syphilis, as I shall show, the probability of progression, relapse, or death is reduced from a probable $25-30$ percent without treatment to about 5 percent with it; and the gravity of the relapse if it occurs, is markedly diminished.28

"Another compelling reason for treatment," noted Moore, "exists in the fact that every patient with latent syphilis may be, and perhaps is, infectious for others." 99 In 1932, the year in which the Tuskegee Study began, the USPHS sponsored and published a paper by Moore and six other syphilis experts that strongly argued for treating latent syphilis. ${ }^{30}$

The Oslo Study, therefore, could not have provided justification for the USPHS to undertake a study that did not entail treatment. Rather, the suppositions that conditions in Tuskegee existed "naturally" and that the men would not be treated anyway provided the experiment's rationale. In turn, these two assumptions rested on the prevailing medical attitudes concerning blacks, sex, and disease. For example, Clark explained the prevalence of venereal disease in Macon County by emphasizing promiscuity among blacks:

This state of affairs is due to the paucity of doctors, rather low intelligence of the Negro population in this section, depressed economic conditions, and the very common promiscuous sex relations of this population group which not only contribute to the spread of syphilis but also contribute to the prevailing indifference with regard to treatment. ${ }^{31}$

In fact, Moore, who had written so persuasively in favor of treating latent syphilis, suggested that existing knowledge did not apply to Negroes. Although he had called the Oslo Study "a never-to-be-repeated human experiment," ${ }_{32}$ he served as an expert consultant to the Tuskegee Study:

I think that such a study as you have contemplated would be of immense value. It will be necessary of course in the consideration of the results to evaluate the special factors introduced by a selection of the material from negro males. Syphilis in the negro is in many respects almost a different disease from syphilis in the white. ${ }^{33}$

Dr. O. C. Wenger, chief of the federally operated venereal disease clinic at Hot Springs, Arkansas, praised Moore's judgment, adding, "This study will emphasize those differences." 34 On another occasion he advised Clark, "We must remember we are dealing with a group of people who are illiterate, have no conception of time, and whose personal history is always indefinite." ${ }^{35}$

The doctors who devised and directed the Tuskegee Study accepted the mainstream assumptions regarding blacks and venereal disease. The premise that blacks, promiscuous and lustful, would not seek or continue treatment, shaped the study. A test of untreated syphilis seemed "natural" because the USPHS presumed the men would never be treated; the Tuskegee Study made that a self-fulfilling prophecy.

\section{Selecting the Subjects}

Clark sent Dr. Raymond Vonderlehr to Tuskegee in September 1932 to assemble a sample of men with latent syphilis for the experiment. The basic design of the study called for the selection of syphilitic black males between the ages of twenty-five and sixty, a thorough physical examination including $x$-rays, and finally, a spinal tap to determine the incidence of neuro-syphilis. ${ }^{36}$ They had no intention of providing any treatment for the infected men. ${ }^{3 i}$ The USPHS originally scheduled the whole experiment to last six months; it seemed to be both a simple and inexpensive project.

The task of collecting the sample, however, proved to be more difficult than the USPHS had supposed. Vonderlehr canvassed the largely illiterate, poverty-stricken population of sharecroppers and tenant farmers in search of test subjects. If his circulars requested only men over twenty-five to attend his clinics, none would appear, suspecting he was conducting draft physicals. Therefore, he was forced to test large numbers of women and men who did not fit the experiment's specifications. This involved considerable expense since the USPHS had promised the Macon County Board of Health that it would treat those who were infected, but not included in the study.$^{38}$ Clark wrote to Vonderlehr about the situation: "It never once occured to me that we would be called upon to treat a large part of the county as return for the privilege of making this study. ... I am anxious to keep the expenditures for treatment down to the lowest possible point because it is the one item of expenditure in connection with the study most difficult to defend despite our knowledge of the need therefor." ${ }^{39}$ Vonderlehr responded: "If we could find from 100 to 200 cases ... we would not have to do another Wassermann on useless individuals . .." 40 
Significantly, the attempt to develop the sample contradicted the prediction the USPHS had made initially regarding the prevalence of the disease in Macon County. Overall rates of syphilis fell well below expectations; as opposed to the USPHS projection of 35 percent, 20 percent of those tested were actually diseased. ${ }^{41}$ Moreover, those who had sought and received previous treatment far exceeded the expectations of the USPHS. Clark noted in a letter to Vonderlehr:

I find your report of March 6th quite interesting but regret the necessity for Wassermanning [sic] . . . such a large number of individuals in order to uncover this relatively limited number of untreated cases. ${ }^{42}$

Further difficulties arose in enlisting the subjects to participate in the experiment, to be "Wassermanned," and to return for a subsequent series of examinations. Vonderlehr found that only the offer of treatment elicited the cooperation of the men. They were told they were ill and were promised free care. Offered therapy, they became willing subjects. ${ }^{43}$ The USPHS did not tell the men that they were participants in an experiment; on the contrary, the subjects believed they were being treated for "bad blood"- the rural South's colloquialism for syphilis. They thought they were participating in a public health demonstration similar to the one that had been conducted by the Julius Rosenwald Fund in Tuskegee several years earlier. In the end, the men were so eager for medical care that the number of defaulters in the experiment proved to be insignificant. ${ }^{44}$

To preserve the subjects' interest, Vonderlehr gave most of the men mercurial ointment, a noneffective drug, while some of the younger men apparently received inadequate dosages of neoarsphenamine. ${ }^{45}$ This required Vonderlehr to write frequently to Clark requesting supplies. He feared the experiment would fail if the men were not offered treatment.

It is desirable and essential if the study is to be a success to maintain the interest of each of the cases examined by me through to the time when the spinal puncture can be completed. Expenditure of several hundred dollars for drugs for these men would be well worth while if their interest and cooperation would be maintained in so doing. . . . It is my desire to keep the main purpose of the work from the negroes in the county and continue their interest in treatment. That is what the vast majority wants and the examination seems relatively unimportant to them in comparison. It would probably cause the entire experiment to collapse if the clinics were stopped before the work is completed. ${ }^{46}$

On another occasion he explained:

Dozens of patients have been sent away without treatment during the past two weeks and it would have been impossible to continue without the free distribution of drugs because of the unfavorable impression made on the negro. ${ }^{47}$

The readiness of the test subjects to participate of course contradicted the notion that blacks would not seek or continue therapy.

The final procedure of the experiment was to be a spinal tap to test for evidence of neuro-syphilis. The USPHS presented this purely diagnostic exam, which often entails considerable pain and complications, to the men as a "special

\section{treatment." Clark explained to Moore:}

We have not yet commenced the spinal punctures. This operation will be deferred to the last in order not to unduly disturb our field work by any adverse reports by the patients subjected to spinal puncture because of some disagreeable sensations following this procedure. These negroes are very ignorant and easily influenced by things that would be of minor significance in a more intelligent group. ${ }^{48}$

The letter to the subjects announcing the spinal tap read:

Some time ago you were given a thorough examination and since that time we hope you have gotten a great deal of treatment for bad blood. You will now be given your last chance to get a second examination. This examination is a very special one and after it is finished you will be given a special treatment if it is believed you are in a condition to stand it....

Remember This Is Your Last Chance for Special Free Treatment. Be Sure To Meet The Nurse. ${ }^{49}$

The HEW investigation did not uncover this crucial fact: the men participated in the study under the guise of treatment.

Despite the fact that their assumption regarding prevalence and black attitudes toward treatment had proved wrong, the USPHS decided in the summer of 1933 to continue the study. Once again, it seemed only "natural" to pursue the research since the sample already existed, and with a depressed economy, the cost of treatment appeared prohibitive-although there is no indication it was ever considered. Vonderlehr first suggested extending the study in letters to Clark and Wenger:

At the end of this project we shall have a considerable number of cases presenting various complications of syphilis, who have received only mercury and may still be considered untreated in the modern sense of therapy. Should these cases be followed over a period of from five to ten years many interesting facts could be learned regarding the course and complications of untreated syphilis. ${ }^{50}$

"As I see it," responded Wenger, "we have no further interest in these patients until they die." " Apparently, the physicians engaged in the experiment believed that only autopsies could scientifically confirm the findings of the study. Surgeon General Cumming explained this in a letter to R. R. Moton, requesting the continued cooperation of the Tuskegee Institute Hospital:

This study which was predominantly clinical in character points to the frequent occurrence of severe complications involving the various vital organs of the body and indicates that syphilis as a disease does a great deal of damage. Since clinical observations are not considered final in the medical world, it is our desire to continue observation on the cases selected for the recent study and if possible to bring a percentage of these cases to autopsy so that pathological confirmation may be made of the disease processes. ${ }^{52}$

Bringing the men to autopsy required the USPHS to devise a further series of deceptions and inducements. Wenger warned Vonderlehr that the men must not realize that they would be autopsied: 
There is one danger in the latter plan and that is if the colored population become aware that accepting free hospital care means a post-mortem, every darkey will leave Macon County and it will hurt [Dr. Eugene] Dibble's hospital. ${ }^{53}$

"Naturally," responded Vonderlehr, "it is not my intention to let it be generally known that the main object of the present activities is the bringing of the men to necropsy." The subjects' trust in the USPHS made the plan viable. The USPHS gave Dr. Dibble, the Director of the Tuskegee Institute Hospital, an interim appointment to the Public Health Service. As Wenger noted:

One thing is certain. The only way we are going to get postmortems is to have the demise take place in Dibble's hospital and when these colored folks are told that Doctor Dibble is now a Government doctor too they will have more confidence. ${ }^{55 *}$

After the USPHS approved the continuation of the experiment in 1933, Vonderlehr decided that it would be necessary to select a group of healthy, uninfected men to serve as controls. Vonderlehr, who had succeeded Clark as Chief of the Venereal Disease Division, sent Dr. J. R. Heller to Tuskegee to gather the control group. Heller distributed drugs (noneffective) to these men, which suggests that they also believed they were undergoing treatment. ${ }^{56}$ Control subjects who became syphilitic were simply transferred to the test group - a strikingly inept violation of standard research procedure. ${ }^{5 \tau}$

The USPHS offered several inducements to maintain contact and to procure the continued cooperation of the men. Eunice Rivers, a black nurse, was hired to follow their health and to secure approval for autopsies. She gave the men noneffective medicines-"spring tonic" and aspirin-as well as transportation and hot meals on the days of their examinations. ${ }^{58}$ More important, Nurse Rivers provided continuity to the project over the entire forty-year period. By supplying "medicinals," the USPHS was able to continue to deceive the participants, who believed that they were receiving therapy from the government doctors. Deceit was integral to the study. When the test subjects complained about spinal taps one doctor wrote:

\footnotetext{
*The degree of black cooperation in conducting the study remains unclear and would be impossible to properly assess in an article of this length. It seems certain that some members of the Tuskegee Institute staff such as R. R. Moton and Eugene Dibble understood the nature of the experiment and gave their support to it. There is, however, evidence that some blacks who assisted the USPHS physicians were not aware of the deceptive nature of the experiment. Dr. Joshua Williams, an intern at the John A. Andrew Memorial Hospital (Tuskegee Institute) in 1932, assisted Vonderlehr in taking blood samples of the test subjects. In 1973 he told the HEW panel: "I know we thought it was merely a service group organized to help the people in the area. We didn't know it was a research project at all at the time." (See, "Transcript of Proceedings," Tuskegee Syphilis Study Ad Hoc Advisory Panel, February 23, 1973, Unpublished typescript. National Library of Medicine, Bethesda, Maryland.) It is also apparent that Eunice Rivers, the black nurse who had primary responsibility for maintaining contact with the men over the forty years, did not fully understand the dangers of the experiment. In any event, black involvement in the study in no way mitigates the racial assumptions of the experiment, but rather, demonstrates their power.
}

They simply do not like spinal punctures. A few of those who were tapped are enthusiastic over the results but to most, the suggestion causes violent shaking of the head; others claim they were robbed of their procreative powers (regardless of the fact that I claim it stimulates them) .59

Letters to the subjects announcing an impending USPHS visit to Tuskegee explained: "[The doctor] wants to make a special examination to find out how you have been feeling and whether the treatment has improved your health." 60 In fact, after the first six months of the study, the USPHS had furnished no treatment whatsoever.

Finally, because it proved difficult to persuade the men to come to the hospital when they became severely ill, the USPHS promised to cover their burial expenses. The Milbank Memorial Fund provided approximately $\$ 50$ per man for this purpose beginning in 1935. This was a particularly strong inducement as funeral rites constituted an important component of the cultural life of rural blacks. ${ }^{61}$ One report of the study concluded, "Without this suasion it would, we believe, have been impossible to secure the cooperation of the group and their families." 62

Reports of the study's findings, which appeared regularly in the medical press beginning in 1936, consistently cited the ravages of untreated syphilis. The first paper, read at the 1936 American Medical Association annual meeting, found "that syphilis in this period [latency] tends to greatly increase the frequency of manifestations of cardiovascular disease." 63 Only 16 percent of the subjects gave no sign of morbidity as opposed to 61 percent of the controls. Ten years later, a report noted coldly, "The fact that nearly twice as large a proportion of the syphilitic individuals as of the control group has died is a very striking one." Life expectancy, concluded the doctors, is reduced by about 20 percent. ${ }^{64}$

A 1955 article found that slightly more than 30 percent of the test group autopsied had died directly from advanced syphilitic lesions of either the cardiovascular or the central nervous system. ${ }^{65}$ Another published account stated, "Review of those still living reveals that an appreciable number have late complications of syphilis which probably will result, for some at least, in contributing materially to the ultimate cause of death." "66 In 1950, Dr. Wenger had concluded, "We now know, where we could only surmise before, that we have contributed to their ailments and shortened their lives." As black physician Vernal Cave, a member of the HEW panel, later wrote, "They proved a point, then proved a point, then proved a point." 68

During the forty years of the experiment the USPHS had sought on several occasions to ensure that the subjects did not receive treatment from other sources. To this end, Vonderlehr met with groups of local black doctors in 1934, to ask their cooperation in not treating the men. Lists of subjects were distributed to Macon County physicians along with letters requesting them to refer these men back to the USPHS if they sought care. ${ }^{69}$ The USPHS warned the Alabama Health Department not to treat the test subjects when they took a mobile VD unit into Tuskegee in the early 1940s. ${ }^{70}$ In 1941, the Army drafted several subjects and told them to begin antisyphilitic treatment immediately. The 
USPHS supplied the draft board with a list of 256 names they desired to have excluded from treatment, and the board complied. ${ }^{71}$

In spite of these efforts, by the early 1950s many of the men had secured some treatment on their own. By 1952, almost 30 percent of the test subjects had received some penicillin, although only 7.5 percent had received what could be considered adequate doses. ${ }^{72}$ Vonderlehr wrote to one of the participating physicians, "I hope that the availability of antibiotics has not interfered too much with this project." A report published in 1955 considered whether the treatment that some of the men had obtained had "defeated" the study. The article attempted to explain the relatively low exposure to penicillin in an age of antibiotics, suggesting as a reason: "the stoicism of these men as a group; they still regard hospitals and medicines with suspicion and prefer an occasional dose of time-honored herbs or tonics to modern drugs." ${ }^{2}$ The authors failed to note that the men believed they already were under the care of the government doctors and thus saw no need to seek treatment elsewhere. Any treatment which the men might have received, concluded the report, had been insufficient to compromise the experiment.

When the USPHS evaluated the status of the study in the 1960s they continued to rationalize the racial aspects of the experiment. For example, the minutes of a 1965 meeting at the Center for Disease Control recorded:

Racial issue was mentioned briefly. Will not affect the study. Any questions can be handled by saying these people were at the point that therapy would no longer help them. They are getting better medical care than they would under any other circumstances. ${ }^{75}$

A group of physicians met again at the CDC in 1969 to de-

\section{Claude Bernard on Human Experimentation (1865)}

Experiments, then, may be performed on man, but within what limits? It is our duty and our right to perform an experiment on man whenever it can save his life, cure him or gain him some personal benefit. The principle of medical and surgical morality, therefore, consists in never performing on man an experiment which might be harmful to him to any extent, even though the result might be highly advantageous to science, i.e., to the health of others. But performing experiments and operations exclusively from the point of view of the patient's own advantage does not prevent their turning out profitably to science. ... For we must not deceive ourselves, morals do not forbid making experiments on one's neighbor or on one's self. Christian morals forbid only one thing, doing ill to one's neighbor. So, among the experiments that may be tried on man, those that can only harm are forbidden, those that are innocent are permissible, and those that may do good are obligatory. Claude Bernard, An Introduction to the Study of Experimental Medicine (1865). Trans. by Henry $C$. Green (New York: Dover Publications, 1957). cide whether or not to terminate the study. Although one doctor argued that the study should be stopped and the men treated, the consensus was to continue. Dr. J. Lawton Smith remarked, "You will never have another study like this; take advantage of it." 76 A memo prepared by Dr. James B. Lucas, Assistant Chief of the Venereal Disease Branch, stated: "Nothing learned will prevent, find, or cure a single case of infectious syphilis or bring us closer to our basic mission of controlling venereal disease in the United States." $77 \mathrm{He}$ concluded, however, that the study should be continued "along its present lines." When the first accounts of the experiment appeared in the national press in July 1972, data were still being collected and autopsies performed. ${ }^{78}$

\section{The HEW Final Report}

HEW finally formed the Tuskegee Syphilis Study Ad Hoc Advisory Panel on August 28, 1972, in response to criticism that the press descriptions of the experiment had triggered. The panel, composed of nine members, five of them black, concentrated on two issues. First, was the study justified in 1932 and had the men given their informed consent? Second, should penicillin have been provided when it became available in the early 1950s? The panel was also charged with determining if the study should be terminated and assessing current policies regarding experimentation with human subjects. $^{79}$ The group issued their report in June 1973.

By focusing on the issues of penicillin therapy and informed consent, the Final Report and the investigation betrayed a basic misunderstanding of the experiment's purposes and design. The HEW report implied that the failure to provide penicillin constituted the study's major ethical misjudgment; implicit was the assumption that no adequate therapy existed prior to penicillin. Nonetheless medical authorities

\section{From the HEW Final Report (1973)}

1. In retrospect, the Public Health Service Study of Untreated Syphilis in the Male Negro in Macon County, Alabama, was ethically unjustified in 1932. This judgement made in 1973 about the conduct of the study in 1932 is made with the advantage of hindsight acutely sharpened over some forty years, concerning an activity in a different age with different social standards. Nevertheless, one fundamental ethical rule is that a person should not be subjected to avoidable risk of death or physical harm unless he freely and intelligently consents. There is no evidence that such consent was obtained from the participants in this study.

2. Because of the paucity of information available today on the manner in which the study was conceived, designed and sustained, a scientific justification for a short term demonstration study cannot be ruled out. However, the conduct of the longitudinal study as initially reported in 1936 and through the years is judged to be scientifically unsound and its results are disproportionately meager compared with known risks to human subjects involved.... 
firmly believed in the efficacy of arsenotherapy for treating syphilis at the time of the experiment's inception in 1932. The panel further failed to recognize that the entire study had been predicated on nontreatment. Provision of effective medication would have violated the rationale of the experiment-to study the natural course of the disease until death. On several occasions, in fact, the USPHS had prevented the men from receiving proper treatment. Indeed, there is no evidence that the USPHS ever considered providing penicillin.

The other focus of the Final Report-informed consentalso served to obscure the historical facts of the experiment. In light of the deceptions and exploitations which the experiment perpetrated, it is an understatement to declare, as the Report did, that the experiment was "ethically unjustified," because it failed to obtain informed consent from the subjects. The Final Report's statement, "Submitting voluntarily is not informed consent," indicated that the panel believed that the men had volunteered for the experiment. ${ }^{80}$ The records in the National Archives make clear that the men did not submit voluntarily to an experiment; they were told and they believed that they were getting free treatment from expert government doctors for a serious disease. The failure of the HEW Final Report to expose this critical fact-that the USPHS lied to the subjects-calls into question the thoroughness and credibility of their investigation.

Failure to place the study in a historical context also made it impossible for the investigation to deal with the essentially racist nature of the experiment. The panel treated the study as an aberration, well-intentioned but misguided. ${ }^{81}$ Moreover, concern that the Final Report might be viewed as a critique of human experimentation in general seems to have severely limited the scope of the inquiry. The Final Report is quick to remind the reader on two occasions: "The position of the Panel must not be construed to be a general repudiation of scientific research with human subjects." 82 The Report assures us that a better designed experiment could have been justified:

It is possible that a scientific study in 1932 of untreated syphilis, properly conceived with a clear protocol and conducted with suitable subjects who fully understood the implications of their involvement, might have been justified in the prepenicillin era. This is especially true when one considers the uncertain nature of the results of treatment of late latent syphilis and the highly toxic nature of therapeutic agents then available. ${ }^{83}$

This statement is questionable in view of the proven dangers of untreated syphilis known in 1932.

Since the publication of the HEW Final Report, a defense of the Tuskegee Study has emerged. These arguments, most clearly articulated by Dr. R. H. Kampmeier in the Southern Medical Journal, center on the limited knowledge of effective therapy for latent syphilis when the experiment began. Kampmeier argues that by 1950 , penicillin would have been of no value for these men. ${ }^{84}$ Others have suggested that the men were fortunate to have been spared the highly toxic treatments of the earlier period. ${ }^{85}$ Moreover, even these contemporary defenses assume that the men never would have been treated anyway. As Dr. Charles Barnett of Stan- ford University wrote in 1974, "The lack of treatment was not contrived by the USPHS but was an established fact of which they proposed to take advantage." ${ }^{86}$ Several doctors who participated in the study continued to justify the experiment. Dr. J. R. Heller, who on one occasion had referred to the test subjects as the "Ethiopian population," told reporters in 1972:

I don't see why they should be shocked or horrified. There was no racial side to this. It just happened to be in a black community. I feel this was a perfectly straightforward study, perfectly ethical, with controls. Part of our mission as physicians is to find out what happens to individuals with disease and without disease. ${ }^{87}$

These apologies, as well as the HEW Final Report, ignore many of the essential ethical issues which the study poses, The Tuskegee Study reveals the persistence of beliefs within the medical profession about the nature of blacks, sex, and disease-beliefs that had tragic repercussions long after their alleged "scientific" bases were known to be incorrect. Most strikingly, the entire health of a community was jeopardized by leaving a communicable disease untreated. ${ }^{88}$ There can be little doubt that the Tuskegee researchers regarded their subjects as less than human. ${ }^{89}$ As a result, the ethical canons of experimenting on human subjects were completely disregarded.

The study also raises significant questions about professional self-regulation and scientific bureaucracy. Once the USPHS decided to extend the experiment in the summer of 1933 , it was unlikely that the test would be halted short of the men's deaths. The experiment was widely reported for forty years without evoking any significant protest within the medical community. Nor did any bureaucratic mechanism exist within the government for the periodic reassessment of the Tuskegee experiment's ethics and scientific value. The USPHS sent physicians to Tuskegee every several years to check on the study's progress, but never subjected the morality or usefulness of the experiment to serious scrutiny. Only the press accounts of 1972 finally punctured the continued rationalizations of the USPHS and brought the study to an end. Even the HEW investigation was compromised by fear that it would be considered a threat to future human experimentation.

In retrospect the Tuskegee Study revealed more about the pathology of racism than it did about the pathology of syphilis; more about the nature of scientific inquiry than the nature of the disease process. The injustice committed by the experiment went well beyond the facts outlined in the press and the HEW Final Report. The degree of deception and damages have been seriously underestimated. As this history of the study suggests, the notion that science is a value-free discipline must be rejected. The need for greater vigilance in assessing the specific ways in which social values and attitudes affect professional behavior is clearly indicated.

\section{REFERENCES}

${ }^{1}$ The best general accounts of the study are "The 40-Year Death Watch," Medical World News (August 18, 1972), pp. 15-17; and 
Dolores Katz, "Why 430 Blacks with Syphilis Went Uncured for 40 Years," Detroit Free Press (November 5, 1972). The mortality figure is based on a published report of the study which appeared in 1955 . See Jesse J. Peters, James H. Peers, Sidney Olansky, John C. Cutler, and Geraldine Gleeson, "Untreated Syphilis in the Male Negro: Pathologic Findings in Syphilitic and Nonsyphilitic Patients," Journal of Chronic Diseases 1 (February 1955), 127-48. The article estimated that 30.4 percent of the untreated men would die from syphilitic lesions.

${ }^{2}$ Final Report of the Tuskegee Syphilis Study Ad Hoc Advisory Panel, Department of Health, Education, and Welfare (Washington, D.C.: GPO, 1973). (Hereafter, HEW Final Report).

3See George M. Frederickson, The Black Image in the White Mind (New York: Harper and Row, 1971), pp. 228-55. Also, John H. Haller, Outcasts From Evolution (Urbana, Ill.: University of Illinois Press, 1971), pp. 40-68.

${ }^{4}$ Frederickson, pp. 247-49.

5 "Deterioration of the American Negro," Atlanta Journal-Record of Medicine 5 (July 1903), 287-88. See also J. A. Rodgers, "The Effect of Freedom upon the Psychological Development of the Negro," Proceedings of the American Medico-Psychological Association 7 (1900), 88-99. "From the most healthy race in the country forty years ago," concluded Dr. Henry McHatton, "he is today the most diseased." "The Sexual Status of the Negro-Past and Present," American Journal of Dermatology and Genito-Urinary Diseases 10 (January 1906), 7-9.

${ }^{6 W}$. T. English, "The Negro Problem from the Physician's Point of View," Atlanta Journal-Record of Medicine 5 (October 1903), 461. See also, "Racial Anatomical Peculiarities," New York Medical Journal 63 (April 1896), 500-01.

7"Racial Anatomical Peculiarities," p. 501. Also, Charles S. Bacon, "The Race Problem," Medicine (Detroit) 9 (May 1903), 338-43.

${ }^{8}$ H. H. Hazen, "Syphilis in the American Negro," Journal of the American Medical Association 63 (August 8, 1914), 463. For deeper background into the historical relationship of racism and sexuality see Winthrop D. Jordan, White Over Black (Chapel Hill: University of North Carolina Press, 1968; Pelican Books, 1969), pp. 32-40.

${ }^{9}$ Daniel David Quillian, "Racial Peculiarities: A Cause of the Prevalence of Syphilis in Negroes," American Journal of Dermatology and Genito-Urinary Diseases 10 (July 1906), p. 277.

10 English, p. 463.

11William Lee Howard, "The Negro as a Distinct Ethnic Factor in Civilization," Medicine (Detroit) 9 (June 1903), 424. See also, Thomas W. Murrell, "Syphilis in the American Negro," Journal of the American Medical Association 54 (March 12, 1910), 848.

12"Castration Instead of Lynching," Atlanta Journal-Record of Medicine 8 (October 1906), 457. The editorial added: "The badge of disgrace and emasculation might be branded upon the face or forehead, as a warning, in the form of an 'R,' emblematic of the crime for which this punishment was and will be inflicted."

${ }^{13}$ Searle Harris, "The Future of the Negro from the Standpoint of the Southern Physician," Alabama Medical Journal 14 (January 1902), 62. Other articles on the prevalence of venereal disease among blacks are: H. L. McNeil, "Syphilis in the Southern Negro," Journal of the American Medical Association 67 (September 30, 1916), 100104; Ernest Philip Boas, "The Relative Prevalence of Syphilis Among Negroes and Whites," Social Hygiene 1 (September 1915), 610-16. Doctors went to considerable trouble to distinguish the morbidity and mortality of various diseases among blacks and whites. See, for example, Marion M. Torchia, "Tuberculosis Among American Negroes: Medical Research on a Racial Disease, 1830-1950," Journal of the History of Medicine and Allied Sciences 32 (July 1977), 252-79.

14Thomas W. Murrell, "Syphilis in the Negro: Its Bearing on the Race Problem," American Journal of Dermatology and Genito-Urinary Diseases 10 (August 1906), 307.

15 "Even among the educated, only a very few will carry out the most elementary instructions as to personal hygiene. One thing you cannot do, and that is to convince the negro that he has a disease that he cannot see or feel. This is due to lack of concentration rather than lack of faith; even if he does believe, he does not care; a child of fancy, the sensations of the passing hour are his only guides to the future." Murrell, "Syphilis in the American Negro," p. 847.
16 "Deterioration of the American Negro," Atlanta Journal-Record of Medicine 5 (July 1903), 288.

${ }^{17}$ Murrell, "Syphilis in the Negro; Its Bearing on the Race Problem," p. 307.

18"The anatomical and physiological conditions of the African must be understood, his place in the anthropological scale realized, and his biological basis accepted as being unchangeable by man, before we shall be able to govern his natural uncontrollable sexual passions." See, "As Ye Sow That Shall Ye Also Reap," Atlanta Journal-Record of Medicine 1 (June 1899), 266.

19Taliaferro Clark, The Control of Syphilis in Southern Rural Areas (Chicago: Julius Rosenwald Fund, 1932), 53-58. Approximately 35 percent of the inhabitants of Macon County who were examined were found to be syphilitic.

${ }^{20}$ See Claude Bernard, An Introduction to the Study of Experimental Medicine (New York: Dover, 1865, 1957), pp. 5-26.

${ }^{21}$ Taliaferro Clark to M. M. Davis, October 29, 1932. Records of the USPHS Venereal Disease Division, Record Group 90, Box 239, National Archives, Washington National Record Center, Suitland, Maryland. (Hereafter, NA-WNRC). Materials in this collection which relate to the early history of the study were apparently never consulted by the HEW investigation. Included are letters, reports, and memoranda written by the physicians engaged in the study.

${ }^{22}$ H. S. Cumming to R. R. Moton, September 20, 1932, NAWNRC.

${ }^{23}$ Clark to Davis, October 29, 1932, NA-WNRC.

${ }^{24}$ Cumming to Moton, September 20, 1932, NA-WNRC.

${ }^{25}$ Bruusgaard was able to locate 309 living patients, as well as records from 164 who were diseased. His findings were published as "Ueber das Schicksal der nicht specifizch behandelten Luetiken," Archives of Dermatology and Syphilis 157 (1929), 309-32. The best discussion of the Boeck-Bruusgaard data is E. Gurney Clark and Niels Danbolt, "The Oslo Study of the Natural History of Untreated Syphilis," Journal of Chronic Diseases 2 (September 1955), 311-44.

${ }^{26}$ Joseph Earle Moore, The Modern Treatment of Syphilis (Baltimore: Charles C. Thomas, 1933), p. 24.

27Moore, pp. 231-47; see also John H. Stokes, Modern Clinical Syphilology (Philadelphia: W. B. Saunders, 1928), pp. 231-39.

28 Moore, p. 237.

29Moore, p. 236.

30J. E. Moore, H. N. Cole, P. A. O'Leary, J. H. Stokes, U. J. Wile, T. Clark, T. Parran, J. H. Usilton, "Cooperative Clinical Studies in the Treatment of Syphilis: Latent Syphilis," Venereal Disease Information 13 (September 20,1932), 351. The authors also concluded that the latently syphilitic were potential carriers of the disease, thus meriting treatment.

${ }^{31}$ Clark to Paul A. O'Leary, September 27, 1932, NA-WNRC. O'Leary, of the Mayo Clinic, misunderstood the design of the study, replying: "The investigation which you are planning in Alabama is indeed an intriguing one, particularly because of the opportunity it affords of observing treatment in a previously untreated group. I assure you such a study is of interest to me, and I shall look forward to its report in the future." O'Leary to Clark, October 3, 1932, NAWNRC.

32Joseph Earle Moore, "Latent Syphilis," unpublished typescript (n.d.), p. 7. American Social Hygiene Association Papers, Social Welfare History Archives Center, University of Minnesota, Minneapolis, Minnesota.

33Moore to Clark, September 28, 1932, NA-WNRC. Moore had written in his textbook, "In late syphilis the negro is particularly prone to the development of bone or cardiovascular lesions." See Moore, The Modern Treatment of Syphilis, p. 35.

${ }^{34}$ O. C. Wenger to Clark, October 3, 1932, NA-WNRC.

35 Wenger to Clark, September 29, 1932, NA-WNRC.

${ }^{36}$ Clark Memorandum, September 26, 1932, NA-WNRC. See also, Clark to Davis, October 29, 1932, NA-WNRC.

${ }^{37}$ As Clark wrote: "You will observe that our plan has nothing to do with treatment. It is purely a diagnostic procedure carried out to determine what has happened to the syphilitic Negro who has had no treatment." Clark to Paul A. O'Leary, September 27, 1932, NAWNRC.

s8D. G. Gill to O. C. Wenger, October 10, 1932, NA-WNRC. 
${ }^{39}$ Clark to Vonderlehr, January 25, 1933, NA-WNRC.

40Vonderlehr to Clark, February 28, 1933, NA-WNRC.

41 Vonderlehr to Clark, November 2, 1932, NA-WNRC. Also, Vonderlehr to Clark, February 6, 1933, NA-WNRC.

42Clark to Vonderlehr, March 9, 1933, NA-WNRC.

43Vonderlehr later explained: "The reason treatment was given to many of these men was twofold: First, when the study was started in the fall of 1932, no plans had been made for its continuation and a few of the patients were treated before we fully realized the need for continuing the project on a permanent basis. Second it was difficult to hold the interest of the group of Negroes in Macon County unless some treatment was given." Vonderlehr to Austin V. Diebert, December 5, 1938, Tuskegee Syphilis Study Ad Hoc Advisory Panel Papers, Box 1, National Library of Medicine, Bethesda, Maryland. (Hereafter, TSS-NLM). This collection contains the materials assembled by the HEW investigation in 1972 .

44Vonderlehr to Clark, February 6, 1933, NA-WNRC.

${ }^{45}$ H. S. Cumming to J. N. Baker, August 5, 1933, NA-WNRC.

46January 22, 1933; January 12, 1933, NA-WNRC.

47 Vonderlehr to Clark, January 28, 1933, NA-WNRC.

${ }^{48}$ Clark to Moore, March 25, 1933, NA-WNRC.

${ }^{49}$ Macon County Health Department, "Letter to Subjects," n.d., NA-WNRC.

50Vonderlehr to Clark, April 8, 1933, NA-WNRC. See also, Vonderlehr to Wenger, July 18,1933 , NA-WNRC.

51 Wenger to Vonderlehr, July 21,1933 , NA-WNRC. The italics are Wenger's.

52Cumming to Moton, July 27, 1933, NA-WNRC.

53Wenger to Vonderlehr, July 21, 1933, NA-WNRC.

54 Vonderlehr to Murray Smith, July 27, 1933, NA-WNRC.

55 Wenger to Vonderlehr, August 5, 1933, NA-WNRC.

56 Vonderlehr to Wenger, October 24, 1933, NA-WNRC. Controls were given salicylates.

${ }^{57}$ Austin V. Diebert and Martha C. Bruyere, "Untreated Syphilis in the Male Negro, III," Venereal Disease Information 27 (December 1946), 301-14.

58Eunice Rivers, Stanley Schuman, Lloyd Simpson, Sidney Olansky, "Twenty-Years of Followup Experience In a Long-Range Medical Study," Public Health Reports 68 (April 1953), 391-95. In this article Nurse Rivers explains her role in the experiment. She wrote: "Because of the low educational status of the majority of the patients, it was impossible to appeal to them from a purely scientific approach. Therefore, various methods were used to maintain their interest. Free medicines, burial assistance or insurance (the project being referred to as 'Miss Rivers' Lodge'), free hot meals on the days of examination, transportation to and from the hospital, and an opportunity to stop in town on the return trip to shop or visit with their friends on the streets all helped. In spite of these attractions, there were some who refused their examinations because they were not sick and did not see that they were being benefitted." (p. 393).

${ }_{59}$ Austin V. Diebert to Raymond Vonderlehr, March 20, 1939, TSS-NLM, Box 1.

${ }^{60}$ Murray Smith to Subjects, (1938), TSS-NLM, Box 1. See also, Sidney Olansky to John C. Cutler, November 6, 1951, TSS-NLM, Box 2.

61The USPHS originally requested that the Julius Rosenwald Fund meet this expense. See Cumming to Davis, October 4, 1934, NAWNRC. This money was usually divided between the undertaker, pathologist, and hospital. Lloyd Isaacs to Raymond Vonderlehr, April 23, 1940, TSS-NLM, Box 1.

${ }_{62}$ Stanley H. Schuman, Sidney Olansky, Eunice Rivers, C. A. Smith, Dorothy S. Rambo, "Untreated Syphilis in the Male Negro: Background and Current Status of Patients in the Tuskegee Study," Journal of Chronic Diseases 2 (November 1955), 555.

${ }^{63}$ R. A. Vonderlehr and Taliaferro Clark, "Untreated Syphilis in the Male Negro," Venereal Disease Information 17 (September 1936), 262.

64J. R. Heller and P. T. Bruyere, "Untreated Syphilis in the Male Negro: II. Mortality During 12 Years of Observation," Venereal Disease Information 27 (February 1946), 34-38.

65Jesse J. Peters, James H. Peers, Sidney Olansky, John C. Cutler, and Geraldine Gleeson, "Untreated Syphilis in the Male Negro: Path- ologic Findings in Syphilitic and Non-Syphilitic Patients," Journal of Chronic Diseases 1 (February 1955), 127-48.

${ }^{66}$ Sidney Olansky, Stanley H. Schuman, Jesse J. Peters, C. A. Smith, and Dorothy S. Rambo, "Untreated Syphilis in the Male Negro, X. Twenty Years of Clinical Observation of Untreated Syphilitic and Presumably Nonsyphilitic Groups," Journal of Chronic Diseases 4 (August 1956), 184.

670. C. Wenger, "Untreated Syphilis in Male Negro," unpublished typescript, 1950, p. 3. Tuskegee Files, Center for Disease Control, Atlanta, Georgia. (Hereafter TF-CDC).

68Vernal G. Cave, "Proper Uses and Abuses of the Health Care Delivery System for Minorities with Special Reference to the Tuskegee Syphilis Study," Journal of the National Medical Association 67 (January 1975), 83.

${ }^{69}$ See for example, Vonderlehr to B. W. Booth, April 18, 1934; Vonderlehr to E. R. Lett, November 20, 1933, NA-WNRC.

70"Transcript of Proceedings-Tuskegee Syphilis Ad Hoc Advisory

Panel," February 23, 1973, unpublished typescript, TSS-NLM, Box 1.

71Raymond Vonderlehr to Murray Smith, April 30, 1942; and Smith to Vonderlehr, June 8, 1942, TSS-NLM, Box 1.

72Stanley H. Schuman, Sidney Olansky, Eunice Rivers, C. A. Smith, and Dorothy S. Rambo, "Untreated Syphilis in the Male Negro: Background and Current Status of Patients in the Tuskegee Study," Journal of Chronic Diseases 2 (November 1955), 550-53.

73Raymond Vonderlehr to Stanley H. Schuman, February 5, 1952. TSS-NLM, Box 2.

${ }^{74}$ Schuman et al., p. 550.

75"Minutes, April 5, 1965" unpublished typescript, TSS-NLM,

Box 1.

76"Tuskegee Ad Hoc Committee Meeting-Minutes, February 6, 1969," TF-CDC.


CDC.

${ }^{78}$ Elizabeth M. Kennebrew to Arnold C. Schroeter, February 24, 1971, TSS-NLM, Box 1.

${ }^{79}$ See Medical Tribune (September 13, 1972), pp. 1, 20; and Report on HEW's Tuskegee Report," Medical World News (September 14, 1973), pp. 57-58.

80HEW Final Report, p. 7.

81The notable exception is Jay Katz's eloquent "Reservations About the Panel Report on Charge 1," HEW Final Report, pp. 14-15.

82HEW Final Report, pp. 8, 12.

${ }^{83}$ HEW Final Report, pp. 8, 12.

${ }^{84}$ See R. H. Kampmeier, "The Tuskegee Study of Untreated Syphilis," Southern Medical Journal 65 (October 1972), 1247-51; and "Final Report on the 'Tuskegee Syphilis Study,'" Southern Medical Journal 67 (November 1974), 1349-53.

${ }^{85}$ Leonard J. Goldwater, "The Tuskegee Study in Historical Perspective," unpublished typescript, TSS-NLM; see also "Treponemes and Tuskegee," Lancet (June 23, 1973), p. 1438; and Louis Lasagna, The VD Epidemic (Philadelphia: Temple University Press, 1975), pp. 64-66.

${ }^{86}$ Quoted in "Debate Revives on the PHS Study," Medical World News (April 19, 1974), p. 37.

${ }^{87}$ Heller to Vonderlehr, November 28, 1933, NA-WNRC; quoted in Medical Tribune (August 23, 1972), p. 14.

${ }^{88}$ Although it is now known that syphilis is rarely infectious after its early phase, at the time of the study's inception latent syphilis was thought to be communicable. The fact that members of the control group were placed in the test group when they became syphilitic proves that at least some infectious men were denied treatment.

${ }^{89}$ When the subjects are drawn from minority groups, especially those with which the researcher cannot identify, basic human rights may be compromised. Hans Jonas has clearly explicated the problem in his "Philosophical Reflections on Experimentation," Daedalus 98 (Spring 1969), 234-37. As Jonas writes: "If the properties we adduced as the particular qualifications of the members of the scientific fraternity itself are taken as general criteria of selection, then one should look for additional subjects where a maximum of identification, understanding, and spontaneity can be expected-that is, among the most highly motivated, the most highly educated, and the least "captive' members of the community." 